\title{
Recurso multimedia para elaborar la presentación de caso en Odontopediatría
}

\section{Multimedial resource to prepare case presentation in pediatric dentistry}

\author{
Alejandra Porras-Zúñiga ${ }^{1}$ \\ Universidad de Costa Rica, Costa Rica
}

Resumen. Este artículo analiza la experiencia del proceso de la planificación, la elaboración y la validación de un recurso multimedial, con el objetivo de brindar al estudiante del curso Clínica de Odontopediatría y Ortodoncia I, de la Licenciatura en Odontología de la Universidad de Costa Rica, una guía teórica y práctica para la elaboración de la presentación de caso del paciente pediátrico. Este estudiante no ha realizado prácticas previas donde integre la información de la anamnesis con los exámenes clínico y radiográfico, lo que se evidencia durante el proceso de la presentación de caso, que revela algunas debilidades tales como la ausencia de información, la falta de orden y de análisis integrado de los registros, provocando errores en el diagnóstico y, por lo tanto, en el plan de tratamiento. El recurso se aplicó durante el segundo semestre del 2016, con un grupo voluntario de 12 estudiantes de cinco grupos diferentes de Clínica, quienes utilizaron el recurso multimedia según su necesidad y disponibilidad luego de una sesión presencial de inducción y validación. Posteriormente, se realizó una segunda sesión de discusión acompañada de un instrumento de validación (cuestionario). Los estudiantes expresaron una valoración muy positiva del recurso multimedia porque les facilita el aprendizaje del orden y la verificación de la documentación, ello favorece la revisión y el análisis de todos los registros necesarios para el diagnóstico y la elaboración del plan de tratamiento.

Palabras clave. Enseñanza multimedia, tecnología educativa, recursos educativos, aprendizaje, odontología, odontopediatría

\begin{abstract}
WeThis article analyzes the experience of the process of planning, elaboration and validation of a multimedia resource, with the objective of providing the student of the course Pediatric Dentistry and Orthodontics I, of the Degree in Dentistry of the University of Costa Rica with a theoretical and practical guide to prepare the pediatric case presentation. The student has not carried out previous practices where he/she integrates the information of the anamnesis with the clinical and radiographic exams, which is evidenced during the process of the case presentation, thus revealing some weaknesses such as lack of information, lack of order and integrated analysis of the records, causing errors in the diagnosis and, therefore, in the treatment plan. The application of the resource took place during the second half of 2016, with a volunteer group of 12 students from 5 different Clinic groups, who used the multimedia resource according to their need and availability after a face-to-face induction and validation session. Subsequently, a second discussion session was held, accompanied by a validation instrument (questionnaire). The students expressed a very positive assessment of the multimedia resource as it facilitates the learning of order and the verification of the documentation favoring revision and analysis of all the necessary records for the diagnosis and the preparation of a treatment plan.
\end{abstract}

Keywords. Multimediateaching, educationaltechnology, educationalresources, learning, odontology, pediatricdentistry

${ }^{1}$ Estudiante de la Maestría en Tecnología Educativa. Instructora de Clínica de Odontopediatría de la Facultad de Odontología de la Universidad de Costa Rica. Dirección electrónica: aleporraszuniga@gmail.com 


\section{Introducción}

El acto de educar implica interacciones muy complejas, las cuales involucran cuestiones simbólicas, afectivas, comunicativas, sociales, de valores, etc. De manera que un profesional de la docencia debe de ser capaz de ayudar propositivamente a otros a aprender, pensar, sentir, actuar (Ramírez, 2005, p. 397).

El planteamiento anterior ilustra la complejidad del acto educativo. La labor docente no termina con la presentación de la materia que se imparte o la transmisión de los contenidos, sino que requiere un planteamiento y planificación de acciones que contribuyan a fortalecer los procesos de construcción del conocimiento. Dentro de las diferentes acciones en este proceso, destaca la aplicación de recursos didácticos que reúnan características quefavorezcan a la población a la cual están dirigidas y que provean una oportunidad de facilitar el aprendizaje por diferentes canales.

El ejercicio docente en ciencias de la salud, y en este caso en odontología, debe apoyar el aprendizaje con propuestas claras, con base en los objetivos establecidos dentro del programa educativo, y dirigidas a la construcción de conocimientos con un especial énfasis en el desarrollo de las habilidades de diagnóstico y de elaboración del plan de tratamiento, habilidades que, como bien resaltan Maroto y Quirós (2010, p. 2), le permitan al discente: "interiorizar los conocimientos y ser capaces de llevarlos a la práctica"; estas propuestas se denominan estrategias de aprendizaje. Díaz y Hernández (2005, p. 400) las llaman "herramientas para promover en los estudiantes un aprendizaje con comprensión" y agrupan aspectos tales como la propuesta de las actividades para el trato de los contenidos, la interacción entre el instructor-tutor y alumnos, los recursos para apoyo didáctico, etc.

Dentro de estas acciones es posible incorporar las Tecnologías de la Información y la Comunicación, en adelante TIC, como apoyo para dichos procesos, ya que generan beneficios como la posibilidad de aprender en espacios físicos diferentes al aula, ofrecen flexibilidad en cuanto al momento en el que los estudiantes interactúan con los recursos educativos o amplían los medios de comunicación para el aprendizaje. Por lo tanto, la aplicación de estrategias mediadas por TIC contribuyen a favorecer al estudiante, al proveerle alternativas didácticas que converjan con sus capacidades, habilidades e intereses, marcando también un ritmo propio de avance. La enseñanza de la odontología puede verse enormemente favorecida con estas estrategias. En la actualidad, el reto de la formación de los profesionales en odontología requiere de alternativas educativas dinámicas, las cuales apoyen los procesos que permitan el desarrollo de las habilidades diagnósticas, la planificación y la ejecución de los tratamientos, donde las destrezas manuales y clínicas son fundamentales y específicas para resolver las demandas que la sociedad y sus pacientes precisan.

Bullón et al. (2009) indican que el peso del componente práctico durante los años de preparación clínica en la enseñanza de la odontología, cuando el alumno es quien asume el tratamiento del paciente bajo la supervisión de un instructor docente, representa casi un $70 \%$ de la carga total y destacan cómo en esta etapa, la incorporación de las TIC puede representar un recurso esencial de apoyo en la docencia. Este artículo desarrolla el proceso de preparación, la aplicación y la validación de un multimedia didáctico, como piloto para la solución de una necesidad identificada en los estudiantes de la Licenciatura en Odontología que cursan la Clínica de Odontopediatría y Ortodoncia I, cuando elaboran la preparación de caso para Odontopediatría.

\section{Necesidad educativa}

Durante los cuatro primeros años de la licenciatura, elestudianteha tenidouna amplia formación teórica. Al iniciar el quinto año, comienza el inter- 
nado clínico y se enfrenta a un proceso de aplicación de los conocimientos en un contexto real: la atención del paciente pediátrico (Porras, 2016).

Gutiérrez (2012) explica que tradicionalmente el proceso clínico inicia con la toma de la información de la anamnesis, el examen clínico y el radiográfico. Porras (2016) complementa explicando que otros registros que el estudiante debe obtener son la información social pertinente, los aspectos relevantes de la alimentación, la higiene y los hábitos. Posteriormente, organiza y elabora el diagnóstico y plan de tratamiento para el menor de edad. Este registro se conoce como "Expediente clínico", el cual está conformado con un número de 15 hojas oficiales y otra de "tratamiento tentativo", la cual no es parte del expediente clínico, pero sí es requisito de la presentación de caso. La papelería y las instrucciones para completarla se encuentran en físico en el propio departamento.

Porras (2016) define la presentación de caso como una exposición evaluada en la cual el discente presenta la información y los registros del paciente luego de analizarlos y estudiarlos para establecer el diagnóstico y el plan de tratamiento que se llevará a cabo. La misma autora resalta que esta es la primera experiencia en los procesos de integración de información y contenidos tanto en un contexto simulado como real -habilidad necesaria para establecer los diagnósticos y planes de tratamiento apropiados en sus pacientes-. Al respecto, Gutiérrez (2012) explica:

Cuando el discente realiza dicha presentación es donde se evidencia una deficiencia y es en ese momento que el instructor utiliza como estrategia didáctica para reforzar las habilidades diagnósticas y el planeamiento dental, enviar al estudiante a que profundice en el tema. El discente por su parte, lo que generalmente hace es recurrir a sus apuntes de años anteriores, los cuales son datos teóricos que no contribuyen a superar la carencia detectada. El Departamento de Odontopediatría no cuenta con un mate- rial de apoyo visual que contribuya a solventar esta situación (p. 2).

Otra afirmación docente sobre la necesidad de apoyar el proceso de preparación de caso de los estudiantes en los cursos de odontología, la realiza Maroto (2010), quien señala:

Al iniciar la práctica de clínica de restaurativa, la presentación de caso constituye, a juicio del autor, uno de los aspectos primordiales por examinar. No solo por la preparación que el estudiante demuestra en relación con el caso particular que está tratando, sino, además, porque esta representa la evaluación diagnóstica necesaria dentro de todo proceso de enseñanza aprendizaje, antes de iniciar un nuevo curso (p. 3).

El momento de la presentación del caso es clave para que el docente analice, evalúe y tome decisiones para fortalecer algunas habilidades en el estudiante, a través de la revisión de literatura, demostraciones o explicaciones adicionales (Maroto, 2010); sin embargo, es posible reforzar con anticipación este proceso. Por lo tanto, con la idea de proporcionar al estudiante una herramienta que sirva de guía y apoyo para preparar y elaborar una presentación de caso, verificar que toda la información necesaria esté completa y ordenada, realizar práctica de diagnóstico y análisis por medio de ejercicios con ilustraciones de casos clínicos, radiografías y fotografías intraorales, surge la propuesta de elaboración y aplicación de un multimedia como herramienta didáctica y piloto para una eventual consolidación de un recurso didáctico para abordar esta necesidad educativa.

\section{Fundamentación pedagógica}

La formación universitaria ha sido permeada por los avances tecnológicos que favorecen la innovación en el campo educativo. Afirmaciones que siguen esa dirección son constantes en la literatura, por ejemplo, la de López (s. f.) “[...] las tecnologías han movido al mundo educativo" $\mathrm{e}$ "[...] internet nos ofrece nuevas posibili- 
dades educativas" (p. 1). También Bullón et al. (2009) afirman: "que la integración de las TIC ha supuesto cambios en los procesos de enseñanza/aprendizaje, han variado las relaciones espacio-temporales entre los profesores y los alumnos $[\ldots]$ por ejemplo, mayor participación de los alumnos, enseñanza menos memorística y el profesor se ha convertido más en guía de los alumnos que en transmisor de información" (p. 23). Estos autores plantean que el docente debe asumir el papel de diseñador de situaciones mediadas de aprendizaje, mientras que el discente tiene que adquirir un rol más activo y constructivo, en el cual ponga en práctica sus capacidades, de forma que aprenda, desaprenda y vuelva a aprender (Bullón et al., 2009).

Las propuestas más participativas y automotivadas están sustentadas en el cognitivismo y el construccionismo. Según Clarés (s. f.), las anteriores teorías favorecen las actividades formativas, interactivas y en contextos más reales.

La teoría del aprendizaje significativo de $\mathrm{Au}$ subel también brinda soporte teórico al desarrollo de esta estrategia y, por lo tanto, del proceso educativo, de manera que se desarrolle de una manera coherente con los principios cognitivistas y construccionistas mencionados y recomienda dar importancia durante este proceso de aprendizaje a lo que el alumno ya sabe y expresa: "Averigüe esto y enseñe consecuentemente" (Ausubel, 1997, p. 2).

Es importante tomar en cuenta los diferentes estilos de aprendizaje; entender cómo aprenden los estudiantes, sus alcances y limitaciones, ya que las diferencias individuales adquieren una importancia primaria. González (2013) utiliza las consideraciones de Martín (2011) para definir los estilos de aprendizaje como:

El modo particular, relativamente estable que posee cada alumno al abordar las tareas de aprendizaje integrando aspectos cognoscitivos, metacognitivos, afectivos, fí- sicos y ambientales que sirven de indicadores de cómo el alumno se aproxima al aprendizaje y se adapta a procesos (p. 52).

En su tesis de grado, "Identificación de los estilos de aprendizaje de los estudiantes de $\mathrm{V}$ año de la Facultad de Odontología, Universidad de Costa Rica", los doctores Ethel Bogarín y Esteban Arce encontraron que, con base en el Modelo de Aprendizaje Experiencial de Kolb, un 46 $\%$ de la población estudiada aprendía en forma reflexiva cuyas actividades preferidas son observar, reflexionar sobre las actividades, reunir información, contar con tiempo para preparar y asimilar. El $23 \%$ de la muestra emplea un estilo pragmático, es decir, favorecen el uso de ejemplos, se concentran en las prácticas, adquieren técnicas aplicables a su trabajo y elaboran planes de acción con resultados inmediatos, entre otros (Arce y Bogarín, 2012). Ambos estilos pueden verse muy favorecidos por el desarrollo del multimedia a través de la evaluación de casos clínicos y la propuesta de ejercicios de diagnóstico; una ventaja más para estos es la utilización de ejemplos de presentaciones de caso realizadas anteriormente por otros estudiantes.

Dentro de los aspectos afectivos, la motivación toma un papel relevante, porque se convierte en un motor que conduce al estudiante a la toma de acciones mediante las cuales puede alcanzar los objetivos educativos. Para conocer cómo alcanzar mayores niveles de motivación, es necesario indagar sobre los intereses y las expectativas del estudiantado, además de trabajar y modificar aspectos como la selección de los contenidos, las metodologías y las actividades (González, 2013). La estrategia empleada debe abrir el abanico de los sistemas de transmisión de la información y los canales de aprendizaje; estimular y motivar al alumno a la exploración e interacción, empleando sistemas más flexibles y dinámicos que favorezcan tanto la individualidad como el trabajo en equipo. 
El proyecto multimedia también se basó en la Teoría de la Programación Neurolingüística, la que toma en cuenta la clasificación de los canales de ingreso de información. Esta teoría favorece la comunicación entre los docentes y los alumnos, mediante las actividades que comprendan las tres vías de acceso a la información: visual, auditiva y táctil (Cazau, 2004; López, Romo y López, 2006).

Canté (2017) explica que el " 80 \% de la información procesada por el cerebro del usuario en Internet proviene de la vista" (p. 1) y que las señales visuales son claves durante el aprendizaje. Este autor recomienda que al desarrollar un producto digital -donde el acceso de la información de manera visual tiene una gran relevancia- el uso de la imagen y el color son elementos de considerable importancia, y los llama "poderosos desencadenantes psicológicos" (Canté, 2017, p. 2), que pueden aprovecharse en beneficio del aprendizaje, al estimular sentimientos y percepciones.

Tomando en cuenta las teorías anteriores y los objetivos de aprendizaje del curso O-0540, se propone un diseño de aprendizaje que se enriquezca de los principios de ambas corrientes, tanto la constructivista, como la cognoscitiva, por medio de un recurso multimedia.

\section{Multimedios en educación de la odontología}

Para definir el recurso multimedia, Cubo, González y Lucero (2003) explican que son:

Recursos informáticos orientados a guardar, organizar y estructurar de un modo flexible e interconectado información de muy diversa naturaleza, imágenes, textos, sonidos, música, animaciones, video, etc., con el objetivo de que el usuario la asimile y construya significativamente sus conocimientos, mediante la interacción y las capacidades que propicia la internet (p. 315).

Con base en la definición anterior, este artículo considera un recurso multimedia educativo a la aplicación de una herramienta informática que permite por medio de un software, la interconexión y la interactividad con la información, la cual es transmitida por dos o más medios de comunicación, texto, video, imágenes, sonido, etc., facilitando al usuario construir su aprendizaje, todo ello obedeciendo a un diseño instruccional.

La utilización de los materiales multimedia interactivos como apoyo pedagógico puede enriquecer el proceso cognitivo y constructivo, debido a su posibilidad de estimular diferentes sentidos y por la posibilidad de que sea un mecanismo de motivación al favorecer en el cognoscente la exploración de sus intereses, siguiendo su ritmo de avance en el aprendizaje y complementando aquellos temas que le resultan más afines (Cabero y Duarte, 1999; Golzarri y Ortiz, 2006). Al lograr esta interactividad, se alcanza la integración de los diferentes códigos de transmisión de la información, lo que permite cierta adaptación para los usuarios, de manera que se aprovechen sus habilidades de memoria visual, auditiva y su comprensión escrita.

En el campo de la educación de la odontología, el estudiante puede lograr más confianza y mejor desempeño en su práctica, complementando y reforzando lo que ha aprendido, pues es posible repasar, practicar y retomar aquellos aspectos que considere necesarios, mejorando sus destrezas, con la ventaja de que dispone de mayor organización de espacio y tiempo, al aprovechar los diferentes sistemas móviles donde es posible observar el material (Golzarri y Ortiz, 2006; Castillo, 2011).

Porras (2016) indica que al ofrecer al estudiante la posibilidad de emplear material de apoyo por medio de un entorno virtual de aprendizaje, se ofrece flexibilidad en tiempo y espacio, permitiendo al estudiante de odontología disponer su dedicación de acuerdo con sus posibilidades. Las actividades con multimedia en odontología fortalecen los aprendizajes dentro y fuera del aula y ejercen una función de "puente que une 
el conocimiento teórico y las destrezas prácticas que necesita tener un odontólogo" (Castillo, 2011, p. 100).

La aplicación de un material multimedia en la elaboración de la presentación de caso integra los conocimientos teóricos con sus destrezas diagnósticas por medio de ejercicios, los cuales el estudiante podría completar con base en sus intereses y necesidades con mayor flexibilidad espacial y de horario. Además, ofrece acceso a los documentos necesarios, los protocolos clínicos, las fuentes de consulta, etc., y a las presentaciones de caso anteriores como formas de ejemplo y consulta, transformando las experiencias de otros estudiantes en un banco de aprendizaje, dado el extenso registro de pacientes y casuística del departamento de odontopediatría de la UCR.

Schwartzman, Eder y Roni (2013) establecieron que una forma importante de aprendizaje en las ciencias de la salud es la construcción a través de la vinculación de lo nuevo con lo que ya se conoce; pero, además, incorporando la realidad del tratamiento en personas, la cual resulta en una situación compuesta con matices humanos $y$ sociales que acaban en enormes diferencias y hacen único a cada diagnóstico y tratamiento, y al mismo tiempo traen un bagaje de experiencias y conocimientos necesarios para continuar creciendo como futuros profesionales en el campo de las ciencias médicas.

Porras (2016) recomienda que en el desarrollo de la primera Clínica de Odontopediatría, en la cual el estudiante aún siente inseguridad y no ha tenido contacto real con el paciente pediátrico, es necesario facilitar alternativas didácticas para favorecer su seguridad y confianza al utilizarlas como insumos de verificación, ayuda y repaso.

Mediante el uso de un sistema de aprendizaje multimedia, se desea favorecer el aprendizaje de los estudiantes de la Clínica de Odontopediatría y Ortodoncia de la Universidad de Cos- ta Rica, de forma que adquieran las habilidades y las destrezas para practicar su profesión con responsabilidad y atender satisfactoriamente las necesidades y demandas en salud oral de la población infantil y adolescente. La utilización de un recurso multimedia solo será eficaz si forma parte de un proyecto, si tiene una finalidad $\mathrm{y}$ es parte de una actividad planificada para alcanzar los objetivos propuestos. Por otra parte, para legitimar su aplicación es necesario tomar en cuenta los recursos tecnológicos de los cuales disponen los estudiantes y sus habilidades y conocimientos para implementarlos.

\section{Metodología}

\section{Diseño y desarrollo del material multimedia}

La estructura organizativa para la elaboración del multimedia consistió en cuatro fases: análisis, elaboración, aplicación y validación.

\section{Contexto educativo.}

\section{Población meta y caracterización.}

Estudiantes de $\mathrm{V}$ año de Licenciatura en Odontología, que cursan la Clínica de Odontopediatría y Ortodoncia I y II, O-0540 y O-0543. Jóvenes entre 20-30 años, que provienen de diferentes partes del país. Inician el proceso de preparación clínica y es su primer año en contacto con el paciente pediátrico.

\section{Objetivos didácticos.}

a. Proveer al estudiante de una guía teórica y práctica para la preparación de presentaciones de caso del paciente pediátrico, por medio de un recurso digital multimedia.

b. Brindar al estudiante una herramienta para la práctica del diagnóstico clínico, por medio de un recurso digital multimedia.

\section{Papel del tutor-instructor.}

- Participar activamente en la preparación de material que considere pertinente para ser incorporado en el multimedia, contenidos, material 
ilustrativo, fotografías, radiografías, montaje de casos clínicos, videos, etc.

- Motivador y generador de espacios de interacción con el multimedia antes de la preparación de casos.

- Resolver dudas y dar retroalimentación a los estudiantes.

\section{Papel del estudiante.}

- El estudiante tiene el rol principal; accederá al recurso según sus intereses y necesidades, reforzando las áreas que considere pertinentes.

- Por otra parte, cuando su instructor lo considere necesario, realizará los ejercicios y prácticas que se le recomienden.

- Se desea que el aprendiente, a partir de sus conocimientos previos, los conceptos claves recientemente elaborados a través del multimedia, su perspectiva cultural y social, logre ejecutar apropiadamente el proceso de diagnóstico y propuesta de plan de tratamiento en el paciente pediátrico, objetivo prioritario de la presentación de caso.

\section{Papel del contexto.}

El contexto está determinado por el curso O-0540, Clínica de Odontopediatría y Ortodoncia I, de la Licenciatura en Odontología, de la Universidad de Costa Rica en la Sede Central Rodrigo Facio y los objetivos generales y específicos planteados anteriormente.

La Licenciatura de Odontología se desarrolla a través de un modelo curricular híbrido entre el modelo innovador y el modelo norteamericano, con un importante componente humanista; del modelo norteamericano se sigue la línea curativa y restauradora, la cual se desarrolla mediante cursos aislados, donde las asignaturas básicas se tratan al inicio de la carrera y luego el proceso de formación avanza a la fase clínica, estructurada por especialidades, entre ellas la odontopediatría (Howard y Jiménez, 2014). Guiado por este modelo, los estudiantes se preparan durante los primeros cuatro años en la base teórica y en el desarrollo de las destrezas motoras que sustentarán los principios clínicos para la atención en el paciente.

Los cursos teóricos de la carrera tienen una metodología presencial y magistral, dentro de los cuales se encuentran Teoría de Odontopediatría I y II, cursos que están orientados a la adquisición de conceptos teóricos para el aprendizaje y formación en la atención del paciente menor de edad.

Posteriormente, el discente inicia la etapa de clínicas y se produce el primer contacto del estudiante con la población pediátrica en el marco de la atención clínica. El estudiante se enfrenta a una etapa en la cual es necesario que integre y analice los conocimientos adquiridos con la nueva información documentada sobre el menor de edad y luego, la aplique para elaborar la presentación de caso, evaluación previa a la atención del paciente.

El recurso multimedia es un recurso didáctico de apoyo para construir la presentación de caso de cada paciente, en el contexto de la enseñanza en la Clínica de Odontopediatría y Ortodoncia I, que ha sido diseñado para que el estudiante recurra a él con base en sus necesidades y tiempo disponible, porque la presentación de caso es elaborada por los alumnos fuera del turno clínico.

\section{Requerimientos tecnológicos.}

Para que el educando pueda interactuar y aprovechar al máximo el material multimedia, es recomendable que tenga destrezas básicas en el uso de tecnologías y, además:

a. Posea conocimientos básicos en el uso de una computadora o tableta electrónica.

b. Tenga acceso a Internet y conocimiento sobre su uso y navegación. 
c. Tenga acceso a una computadora o tableta electrónica.

\section{Elaboración del multimedia.}

\section{Breve descripción.}

Se inicia con una fase diagnóstica que brinda información sobre el conocimiento de base que tienen los estudiantes sobre odontopediatría y diagnóstico oral en el paciente pediátrico, esto favorece la activación de los conocimientos previos que los aprendientes han elaborado y constituyen el punto de partida sobre el cual empezarán a construir los nuevos saberes.

En la etapa introductoria se presenta brevemente el tema, los objetivos esperados, el público meta y la organización de contenido del multimedia. Durante la fase de presentación, se tratan los contenidos, de forma que el alumno tenga acceso a los conceptos que serán reforzados a través de actividades interactivas, esto constituye la fase de construcción y consolidación. Se incluyó una fase de cierre para la práctica y evaluación, la cual considera recomendaciones, reflexiones $\mathrm{y}$ aportes que el estudiante pueda realizar con base en la experiencia desarrollada.

Software utilizado para el desarrollo del multimedia.

La herramienta utilizada fue Exelearning («Exelearning», 2016), herramienta de autor de código libre, en su versión 2.1.

\section{Descripción de los escenarios de interacción.}

Metáfora.

La metáfora es un elemento que contribuye al aprendizaje por medio del refuerzo y la repetición de un mensaje seleccionado (Sandoval, Hernández, Díaz y Badilla, 2008).

La metáfora pedagógica elegida es el expediente clínico acompañado de la imagen de niños y niñas, con la finalidad de reiterar el mensaje de que el expediente clínico en odon- topediatría es un documento clave para la atención del paciente pediátrico y para llevar a cabo la presentación de caso, por eso siempre debe mantenerse completo, actualizado y ordenado. En este se encuentra resumida la historia y necesidades del menor de edad y considera todos los registros que el estudiante ha recolectado del niño o niña, madre y padre, y todos los procedimientos que se han realizado previamente para obtener un correcto diagnóstico. Es una carpeta de información que contiene, también todas las actividades (plan de tratamiento) efectuadas y por realizar y es un reflejo de su construcción de conocimientos. Además, es un documento legal que contiene el consentimiento informado.

La imagen de los niños y la presentación de la imagen en forma de dibujo animado, simboliza el ambiente donde se desarrolla el curso, el cual se especializa en la atención del paciente menor de edad, por tanto, implica múltiples diferencias en cuanto a tratamientos, al manejo de conducta y destrezas del estudiante.

Diseño gráfico.

El diseño gráfico del multimedia fue desarrollado por la autora, con apoyo de imágenes con licencia Creative Commons (CC) y el uso del programa libre Gimp para la manipulación y edición de imágenes.

Una de las finalidades del diseño gráfico es facilitar el aprendizaje (Ricupero, 2007). Dentro de los elementos que deben considerarse, la selección de colores posee gran importancia, por tanto, para su utilización en el multimedia, se consideraron las cualidades y los estudios de psicología del color. Canté (2017) expresa que el color está cargado de información y facilita una experiencia visual común, de tal forma es una fuente de comunicadores visuales, es decir, se recuerdan los colores mejor que las señales verbales o textuales usadas sin su aplicación. Heller (2004) explica que la simbología del color se pro- 
duce por experiencias universales, de lenguajes que han sido interiorizados desde la infancia y adoptados culturalmente. Tomando en cuenta la simbología del color y las sensaciones que pueden estimular, los colores seleccionados para el desarrollo de las imágenes del multimedia, tienen las siguientes cualidades:

- Amarillo con diferentes tonalidades. Simboliza la luz, la sabiduría (Ricupero, 2007; Canté, 2017). Heller (2004) lo relaciona con el entendimiento. Ricupero (2007) lo relaciona con la juventud y explica que en psicología puede utilizarse para aliviar el agobio y motivar a mejorar el rendimiento.

- Color azul: estimula la sensación de confianza y seguridad. Se relaciona con la integridad (Canté, 2017). El color azul simboliza reflexión y trabajo (Martínez, 1979), profundidad y la serenidad (Ricupero, 2007).

- Verde: tiene la virtud de estimular la calma y la tranquilidad (Martínez, 1979; Ricupero, 2007). Favorece la comprensión (Canté, 2017).

- Color rojo: su aplicación tiene la virtud de relacionar valor y perseverancia. Se utiliza en forma discreta porque su uso excesivo puede resultar contraproducente (Canté, 2017). Heller (2004) lo relaciona con la alegría y Ricupero (2007) como impulsor del éxito.

- Color blanco: es el color de base seleccionado para el fondo del multimedia. Simbólicamente representa el bien (Heller, 2004).

Para el desarrollo y tratamiento de la imagen, Canté (2017) recomienda integrar la unión del color con el ambiente del usuario y la tarea que está desarrollando, por lo tanto, se utilizan a través del multimedia diferentes imágenes del expediente y los niños y niñas, potenciando la metáfora pedagógica. Ricupero (2007) también destaca el uso de las figuras a las cuales les da una gran importancia comunicativa.

En el desarrollo del multimedia, se utilizaron imágenes para favorecer el aprendizaje de contenidos y transmitir relaciones entre los elementos, a través de infografías y de fotografías de casos clínicos tomadas de los pacientes de la clínica, por ello cada expediente cuenta con el consentimiento informado autorizado por los padres de familia para el uso de estas imágenes con fines didácticos.

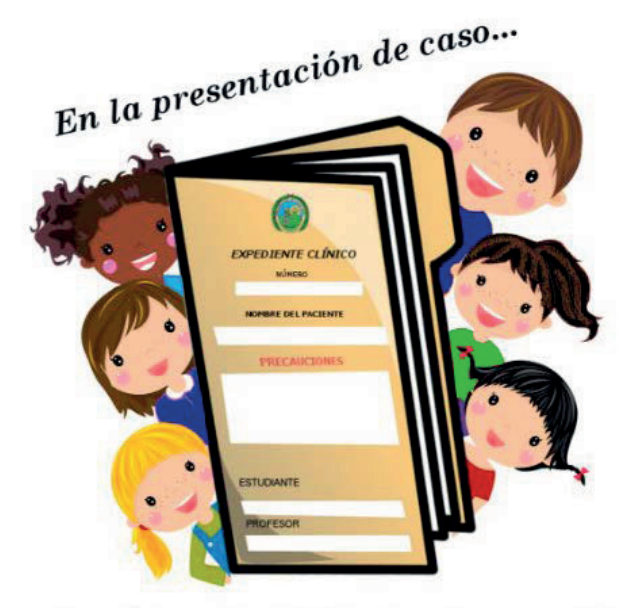

¡Registras la historia de un niño!

Figura 1. Imagen de página de inicio. Nota: elaboración propia 
Cortina de entrada.

Corresponde al preámbulo de la experiencia, a partir de allí el estudiante conocerá los detalles necesarios para la navegación y máximo aprovechamiento del recurso.

Es donde se expone la imagen de la metáfora educativa.

Elmenú principaldenavegación permite visualizarlasáreastemáticas, suorganización, ubicación de las actividades, así como también los créditos.
Con base en la temática seleccionada se despliegan submenús, mediante los cuales se desarrollan actividades y se accede al material de apoyo (audiovisuales, imágenes, hipertextos o vínculos, etc.).

Diagrama de navegación e interacción.

El menú propuesto busca que el estudiante pueda seguir la información sin perderse, que pueda interactuar con el material fácilmente, priorizando sus búsquedas según sus necesida-

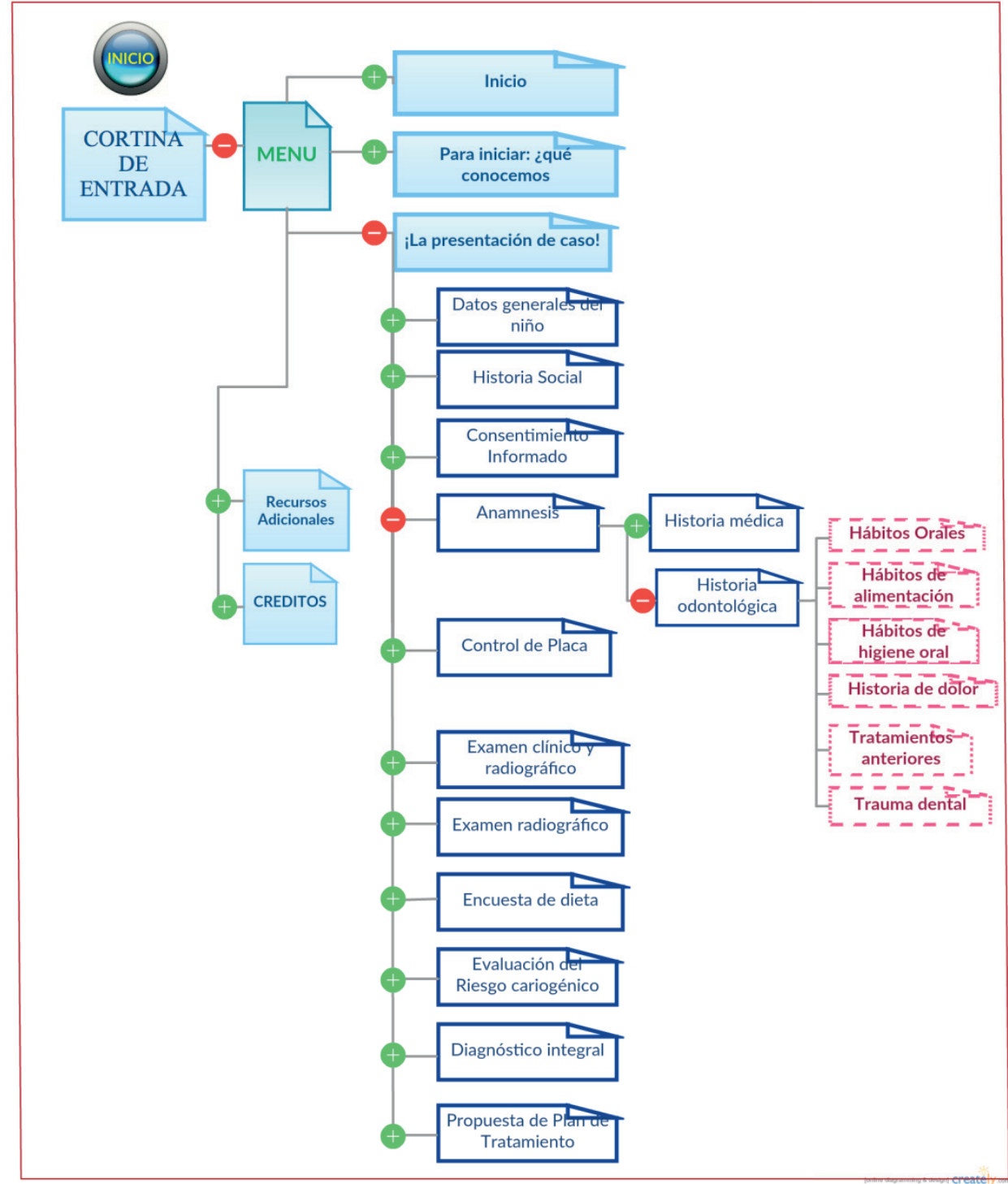

Figura 2. Mapa de navegación para la interacción con el contenido del multimedia. Nota: elaboración propia 
des, de tal forma que se sienta guiado y motivado a su utilización.

Selección de contenidos.

El contenido se presenta en forma de texto, acompañado de contenido audiovisual como imágenes, vídeos, audio y actividades.

El desarrollo del contenido se realiza por medio de módulos, algunos de los cuales se subdividen para desarrollar el tema principal:

Módulo 1. Para iniciar: ¿Qué conocemos?

Cuestionario diagnóstico

Módulo 2. La presentación de caso.

2.1 ¿Qué es la presentación de caso de odontopediatría? tes:

2.2 El expediente clínico y sus par-

a. Datos generales del niño

b. Historia social

c. Consentimiento Informado

d. Anamnesis

i. Historia médica

ii. Historia odontológica

- Queja principal y su historia

- Hábitos orales

- Hábitos de alimentación

- Hábitos de higiene oral

- Tratamientos anteriores

- Trauma dental

e. Control de biofilme dental

f. Examen clínico y radiográfico

g. Encuesta de dieta

h. Evaluación del riesgo cariogénico

i. Diagnóstico integral

j. Plan de tratamiento

Módulo 3. Ejercicios

Módulo 4. Recursos adicionales.
Módulo 5. Créditos

Adaptación de contenido del multimedialelaboración del guion didáctico.

Primero se inició con la esquematización del contenido a través de un guion de contenido. Luego, se continúa con el desarrollo del guion didáctico a partir de la descripción de la cortina de entrada de la herramienta y la interacción con los otros módulos de información. La estructuración de los contenidos $\mathrm{y}$, posteriormente, el desarrollo de la información que se desea presentar permite una comunicación más efectiva y motivadora con el estudiante, lo que mejora la función pedagógica del recurso.

\section{Metodología de aplicación}

La aplicación del recurso se llevó a cabo durante el segundo semestre del año 2016, a un total de doce estudiantes distribuidos en cinco grupos de clínica diferentes. La participación en la validación del recurso fue voluntaria.

La metodología del uso del multimedia "Registra la historia de un niño" fue la siguiente:

\section{Primera sesión}

Semana uno de clínica del II semestre/2016, se realizó una inducción para el uso del multimedia. Se explicó a los estudiantes que se llevaría a cabo una actividad de apoyo y guía para el procedimiento de Presentación de Caso. Para asegurar que los doce estudiantes tuviesen acceso al multimedia, se les consultó si tenían computadora, tableta electrónica y acceso a Internet. El 100 \% respondió que contaba con ambos, por lo tanto, se les facilitó la dirección electrónica http://exelearningpc.alejandraporras.com/ para su visualización. Se les pidió revisar el material, según su disponibilidad de tiempo y lugar, para comentarlo posteriormente.

Segunda sesión

Durante la semana cuatro de clínica del II semestre/2016, se llevó a cabo una discusión sobre 
la aplicación del recurso y se concluyó contestando un cuestionario en forma física (ver anexo 1).

También, se invitó a la interacción con el recurso de forma voluntaria, con base en su motivación, intereses y necesidades. Se explicó que, al finalizar la semana 8 del cronograma, fecha final de presentaciones de caso, se completaría un segundo cuestionario (ver anexo 2).

\section{Resultados}

\section{Validación del multimedia}

Los 12 estudiantes completaron el proceso de validación: participaron en la inducción y completaron ambos cuestionarios.

Mediante el cuestionario 1, se valoraron los indicadores de diseño gráfico y la pertinencia pedagógica del recurso; con el cuestionario 2, se midió la recurrencia deinteracción con el recursoy la percepción del estudiante con respecto a su utilidad.

\section{Resultados del cuestionario 1}

El resultado de la valoración de los estudiantes indica una excelente calificación en los aspectos gráficos del multimedia y una muy buena pertinencia en los aspectos didácticos valorados.

Se utilizaron nueve indicadores de diseño gráfico de los cuales ocho obtuvieron el $100 \%$ de aprobación como "muy apropiados", entre estos el uso de los colores. El noveno indicador, el de definición de la imagen, debe ser revisado pues un $30 \%$ seleccionó "poco", y en sugerencias se hicieron anotaciones, por ejemplo, mejorar la definición en algunas radiografías relacionadas con la práctica de diagnóstico.

En cuanto a los siete indicadores pedagógicos, seis de ellos tuvieron el $100 \%$ de aprobación como "muy adecuados". El indicador de "cantidad de contenido desarrollado" mostró que un $25 \%$ de los estudiantes considera que la cantidad de información que se presenta es "poco adecuada", manifestando una necesidad de mayor cantidad de ejercicios de diagnóstico.

\section{Resultados del cuestionario 2}

Uno de los aspectos más satisfactorios de esta evaluación fue que la totalidad de los estudiantes recurrió al multimedia para elaborar sus presentaciones de caso, en promedio tres veces por estudiante. También en las observaciones anotadas se refleja no solo una mención de partes del multimedia, sino una revisión profunda de su contenido. El $100 \%$ de los participantes recurrieron a la sección partes del expediente clínico. Las secciones más visitadas fueron la de ejercicios diagnósticos (100 \% de los participantes), partes del expediente clínico (100\% de los participantes) y revisión de los protocolos de trabajo clínico (60\% de los participantes).

En respuesta a la segunda parte del cuestionario sobre la sección de mayor provecho y el porqué la seleccionó, las respuestas fueron coincidentes con la pregunta 1; quienes seleccionaron partes del expediente clínico, refieren que les permitió verificar la información y el orden de presentación de los documentos. Asimismo, quienes escogieron ejercicios diagnósticos deseaban prepararse mejor para la discusión durante la presentación de caso y para buscar coincidencias con sus pacientes para establecer los diagnósticos.

Sobre la última sección del cuestionario de recomendaciones, se menciona como una fortaleza que facilita el repaso de contenidos que se han visto previamente en las teorías. En cuanto a sugerencias para mejorar el multimedia, hay consenso sobre colocar más ejercicios para la práctica del diagnósticoy elaboración del plan de tratamiento.

\section{Conclusión}

En el desarrollo de la primera Clínica de Odontopediatría, el estudiante necesita herramientas de apoyo que provean seguridad y confianza, utilizándolas como insumos de verificación, 
ayuda y repaso, y el multimedia es una de ellas. La alta utilización voluntaria del multimedia, el acceso a la sección partes del expediente clínico por la totalidad de los estudiantes y las observaciones que ellos realizan, demuestran que esta herramienta es una necesidad dentro del curso.

El uso de una herramienta multimedia trae beneficios al estudiante como aprovechar el recurso en función de sus necesidades de tiempo y espacio, lo que resulta especialmente beneficioso durante el internado clínico, que demanda de los estudiantes una altísima inversión de tiempo. Se concentra información necesaria, diversa y variada, sin acumulación de papelería, lo que beneficia al departamento, a la facultad, a la Universidad y a la sociedad, pues se reduce el uso de papel. También los contenidos pueden editarse con simplicidad, de manera que se mejore constantemente en función de las necesidades y expectativas de los estudiantes.

$\mathrm{Al}$ facilitar que el estudiante presente toda la documentación necesaria y los registros clínicos completos y ordenados, favorece la integración de contenidos teóricos, prácticos y sociales; también, permitió la práctica de diagnóstico con la sección ejercicios diagnósticos que fue utilizada por la totalidad de los estudiantes, quienes, inclusive, sugieren aumentar la cantidad de estos ejercicios en el multimedia.

\section{Recomendaciones}

- El material fue desarrollado como un piloto. Este será mejorado con las recomendaciones de los estudiantes.

- Se recomienda realizar una posterior validación con los docentes del departamento.

- Es necesario considerar otras alternativas digitales que puedan incorporar tanto la interacción sincrónica como asincrónica, de tal manera que el estudiante reciba retroalimentación oportuna previa a la evaluación de la presentación de caso.

\section{Referencias}

Arce, E. y Bogarín, E. (2012). Identificación de los estilos de aprendizaje de los estudiantes de $V$ año de la Facultad de Odontología, Universidad de Costa Rica. San José: Universidad de Costa Rica.

Ausubel, D. (1997). Teoría del aprendizaje significativo. Fascículos de CEIF, 1-10.

Bullón, P.; Cabero, J.; Llorente, M.; Machuca, M.; Machuca, G. y Román, P. (2009). Utilización de las TIC en la Facultad de Odontología de la Universidad de Sevilla. Sevilla.

Canté, J. F. (2017). Psicologia del color aplicada a los cursos virtuales para mejorar el nivel de aprendizaje en los estudiantes. Grafica, 5(9), 51. https://doi.org/10.5565/rev/grafica.57

Cazau, P. (2004). Estilos de Aprendizaje : generalidades. Chile. Recuperado de http://pcazau.galeon.com/guia_esti

Cubo, S.; González, J. J. y Lucero, M. (2003). Perspectiva pedagógica de los multimedia. Revista Educativa de Pedagogía, 61(225), 309335. Recuperado de http://www.jstor.org/stable/23764980?seq=1\#page_scan_tab_contents

Exelearning. (2016). Exelearning (2.0) [software de computadora]. Recuperado de http:// exelearning.net

Golzarri, A. y Ortiz, R. (2006). Enseñanza de la Odontología. Revista Odontológica Mexicana, $10,138-142$.

Gómez, D. N.; Fulgueira, S. M. y Cerrano, C. M. (2016). Identificación de criterios de calidad para diseño de materiales. Suplemento Signos $E A D, 0(0)$.

González, M. (2013). Los estilos de enseñanza y aprendizaje como soporte de la actividad docente. Journal of Learning Styles, 6(11).

Gutiérrez, N. (2012). Implementación de una estrategia didáctica en la Clínica de Odontopediatría, Facultad de Odontolo- 
gía, UCR. Revista Educación, 36(2), 61-68. https://doi.org/10.15517/revedu.v36i2.5847

Heller, E. (2004). Psicología del color: cómo actuan los colores sobre los sentimientos y la razón. Barcelona: Gustavo Gili. Recuperado de https://dialnet.unirioja.es/servlet/libro? codigo $=254510$

Howard, M. y Jiménez, M. (2014). Análisis Integral del Plan de Estudios de la carrera Licenciatura en Odontología. San José: Universidad de Costa Rica.

López, I.; Romo, M. E. y López, D. (2006). ¿Eres visual, auditivo o kinestésico?: Estilos de aprendizaje desde el modelo de la Programación Neurolingüística (PNL). Revista Iberoamericana de Educación, 38(2), 6.

López, J. C. (s. f.). Propuesta de diseño pedagógico para la elaboración de un programa educativo multimedia. Sevilla. Recuperado de https://cursos.campusvirtualsp.org/pluginfile.php/2177/ mod_resource/content/0/Diseno_Jose_Clarens_Sevilla.pdf

Maroto, O. (2010). Evaluación de la Presentación de Caso, propuesta de una metodologia con rúbrica. Actualidades Investigativas en Educación, 10 (1), 1-22. Recuperado de http://revista. inie.ucr.ac.cr/index.php/aie/article/view/424

Maroto, O. y Quirós, M. (2010). Uso de un medio tecnológico educativo en educación superior como un recurso didáctico: reporte de una experiencia en Odontología. Actualizaciones Investigativas en Educación, 10, 1-21.

Martín-Cuadrado, A. M. (2011). Competencias del estudiante autoregulado y los estilos de aprendizaje. Journal of Learning Styles, 4(8), 136-146. Recuperado de http://learningstyles. uvu.edu/index.php/jls/article/view/68/44
Martínez, A. (1979). Psicología del color. Maina, 0, 35-37. Recuperado de http://www.raco.cat/index.php/Maina/article/view/104120/148287

Porras, A. (2016). La Presentación de Caso en Odontopediatría. San José.

Ramirez, A. (2005). Reseña de estrategias docentes para un aprendizaje significativo de Díaz Barriga y Hernández Rojas. Tiempo de Educar, 6, 397-403. Recuperado de http://www.redalyc.org/articulo.oa?id=31161208

Ricupero, S. (2007). Psicología del color. En Diseño gráfico en el aula : guía de trabajos prácticos. Buenos Aires: Nobuko. Recuperado de https:// books.google.es/books?hl=es\&lr=\&id=_COd0A-851cC\&oi=fnd \&pg $=$ PA9 \& dq = psicología+del+color+diseño+grafico\&ots=D_lHxDPAM3\&sig=ztNLPmRkKZDUXO4MNX2X$0 \mathrm{pYsWLI \#} \mathrm{v}=$ onepage $\& \mathrm{q}=\mathrm{psicología}$ del color diseño grafico $\& \mathrm{f}=$ false

Sánchez, F. M.; Espinosa, M. P.; González, M.; Poveda, L.; Cifuentes, T. y Fernández, I. M. S. (2002). Herramienta de evaluación de multimedia didáctico. Píxel-Bit, Revista de Medios y Educación, 0(18), 71-88.

Sandoval, A. M.; Hernández, D.; Díaz, L. y Badi1la, M. (2008). Metáfora pedagógica. Recuperado 2 de abril de 2017, a partir de http://observatoriotecedu.uned.ac.cr/metafora-pedagogica/

Schwartzman, G.; Eder, M., y Roni, C. (2013). Formación docente en y para la universidad: dispositivos y prácticas en Ciencias de la Salud. Formación docente en y para la universidad: dispositivos y prácticas en Ciencias de la Salud, 12(4), 179-201.

Recibido: 12 de diciembre de 2016 Aceptado: 24 de marzo de 2017 


\section{Anexos}

\section{Anexo 1}

Ficha 1 de Evaluación del multimedia didáctico.

Cuestionario 1. Validación.

\section{Datos de identificación.}

Título: "Registra la historia de un niño"

Asignatura: Odontopediatría y Ortodoncia, curso O-4012

Unidad Académica: Facultad de Odontología

Fecha de producción: I-2016

Fechas de actualización:
Área: Odontología

Nivel educativo: Licenciatura

Fecha de implementación: II-2016

Cuestionario 1: validación multimedia:

"Registra la historia de un niño"

Por favor, marque con una $\mathrm{X}$ según considere apropiado.

\section{VALORACIÓN}

\begin{tabular}{|l|l|l|l|l|}
\hline \multicolumn{1}{|c|}{ Indicadores Diseño Gráfico } & Mucho & Poco & Nada & No aplica \\
\hline La presentación del recurso es agradable & & & & \\
\hline La estructura en pantalla es clara & & & & \\
\hline $\begin{array}{l}\text { La secuencia u orden del multimedia es } \\
\text { apropiada }\end{array}$ & & & & \\
\hline Presenta facilidad de lectura & & & & \\
\hline Presenta colores apropiados & & & & \\
\hline Se observa buena definición en las imágenes & & & & \\
\hline Los recursos audiovisuales son apropiados & & & & \\
\hline Hay facilidad en el manejo de las pantallas & & & & \\
\hline El multimedia despierta interés & & Poco & Nada & No aplica \\
\hline \multicolumn{1}{|c|}{ Indicadores pedagógicos } & Mucho & & & \\
\hline $\begin{array}{l}\text { Le resulta claro que el multimedia está } \\
\text { dirigido a usted }\end{array}$ & & & & \\
\hline Considera que los contenidos son útiles & & & & \\
\hline Podrá aplicar los contenidos & & & & \\
\hline La cantidad de información es adecuada & & & & \\
\hline Los objetivos están claros & & & & \\
\hline Considera que facilita el aprendizaje & & & & \\
\hline $\begin{array}{l}\text { Recomendaría a sus compañeros explorar el } \\
\text { multimedia }\end{array}$ & & & & \\
\hline
\end{tabular}


Responda a las siguientes preguntas.

En los siguientes recuadros, anote las observaciones que considere pertinentes.

1. Sobre diseño:

2. Sobre contenido:

3. Otras recomendaciones:

Elaboración personal con base en Sánchez et al.(2002) y Gómez, Fulgueira, y Cerrano, (2016) 


\section{Anexo 2}

Ficha 2. Evaluación del multimedia didáctico. Utilización

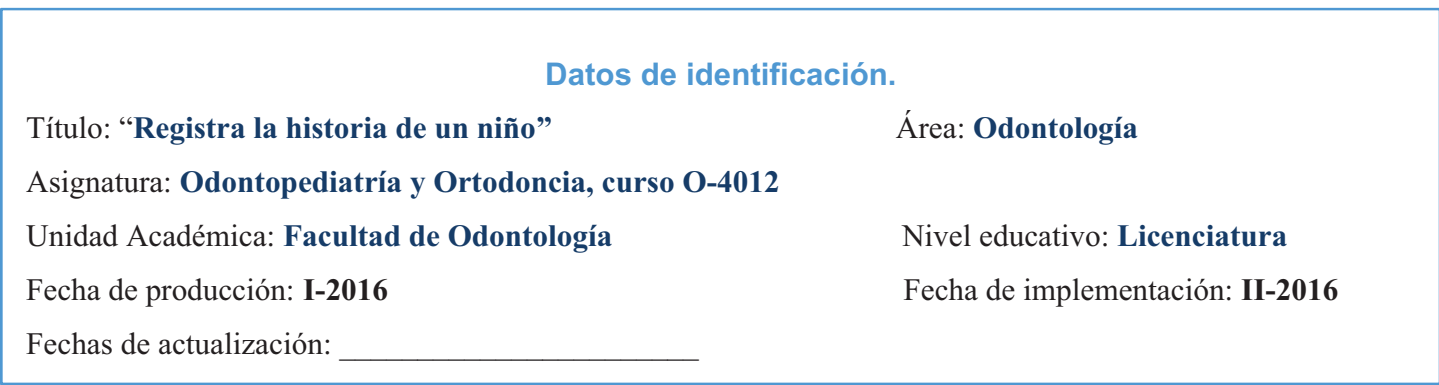

Cuestionario 2. Utilización del multimedia

"Registra la historia de un niño"

Por favor marque con una $\mathrm{X}$ según considere apropiado.

\begin{tabular}{|c|c|c|c|c|}
\cline { 2 - 5 } \multicolumn{1}{c|}{} & \multicolumn{4}{c|}{ VALORACIÓN } \\
\hline Indicadores & 3 o más & 2 o menos & Ninguna & No aplica \\
\hline Número de veces que fue accesado & & & & \\
\hline $\begin{array}{c}\text { Escriba las tres secciones más utilizadas iniciando por la que utilizó el mayor número de } \\
\text { veces }\end{array}$ \\
\hline \multicolumn{4}{|c|}{} \\
\hline
\end{tabular}

¿Cuál sección del multimedia fue de mayor provecho para su aprendizaje y por qué?

¿Tiene usted alguna recomendación o sugerencia para mejorar el multimedia?: 